\title{
Year of the Child
}

\section{John Bunnell Davis and the Universal Dispensary for Children}

\author{
I S L LOUDON
}

British Medical fournal, 1979, 1, 1191-1194

Until 1850, England lagged behind the Continent in the provision of charitable institutions for sick children. ${ }^{1}$ The first was George Armstrong's Dispensary for the Infant Poor, established in 1769. Because it was the first of its kind it has attracted much attention. It was, however, a small single-handed institution run mostly at the founder's own expense, ${ }^{2}$ which ceased soon after he died in January $1789 .^{3}$

Certainly, the Dispensary for the Infant Poor was smaller and much shorter lived than the general dispensaries that followed it-for example, the Aldersgate (1770), the Westminster General (1774), and the Surrey (1777)-which were larger, influential institutions, and the first three of many general dispensaries that followed in rapid succession. Only a few children were seen at these dispensaries, and, while children's hospitals were being established in all the major cities on the Continent, nothing happened in England until the Universal Dispensary for Children at St Andrew's Hill, Doctors' Commons, was established in 1816. Other dispensaries also evolved into hospitals and changed their names in the process, but none so confusingly as the Universal, which became known as : the Universal Dispensary for Children (1816) and the Royal Universal Dispensary for Children (1821)-both at St Andrew's Hill. Then, at Waterloo Bridge Road: the Royal Universal Infirmary for Children (1824) (fig 1), the Royal Infirmary for Children (1843), the Royal Infirmary for Children and Women (1852), the Royal Hospital for Children and Women (1875) (fig 2), and the Royal Waterloo Hospital for Children and Women (1903).

These changes have led to historical confusion and may explain the unjust neglect of the first major institution in England devoted solely to the care of sick children, 35 years before the first children's hospital in Liverpool, and 36 before Great Ormond Street.

\section{The Dispensary and its founder}

The founder of the Universal Dispensary and the driving force behind it during the first eight years was John Buninell Davis. ${ }^{4} \mathrm{He}$ was also physician to the Northern and the Surrey dispensaries, a man of exceptional energy, single-minded and egotistical, with a flair for organisation and publicity-qualities that made him an outstanding medical administrator. His strength lay not only in these qualities, but also in his genuine compassion for sick children and an enthusiasm based on a

Wantage, Oxfordshire OX12 9EH

I S L LOUDON, DM, FRCGP, general practitioner

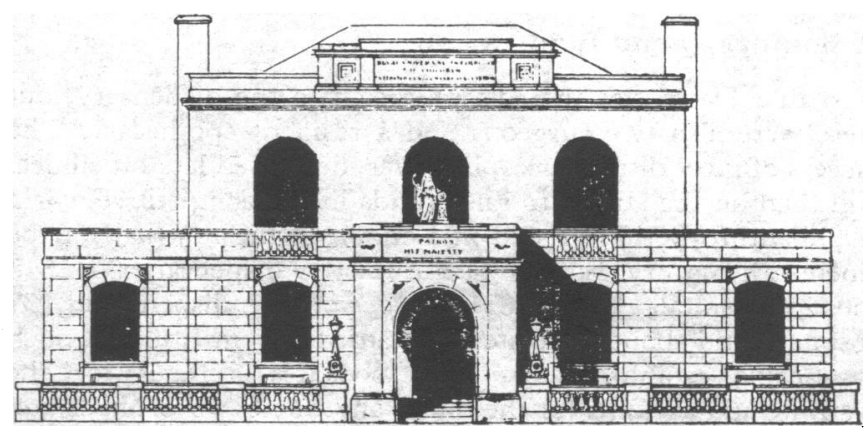

FIG 1-Western elevation of the Royal Universal Infirmary for Children, Waterloo Bridge Road, in 1824.

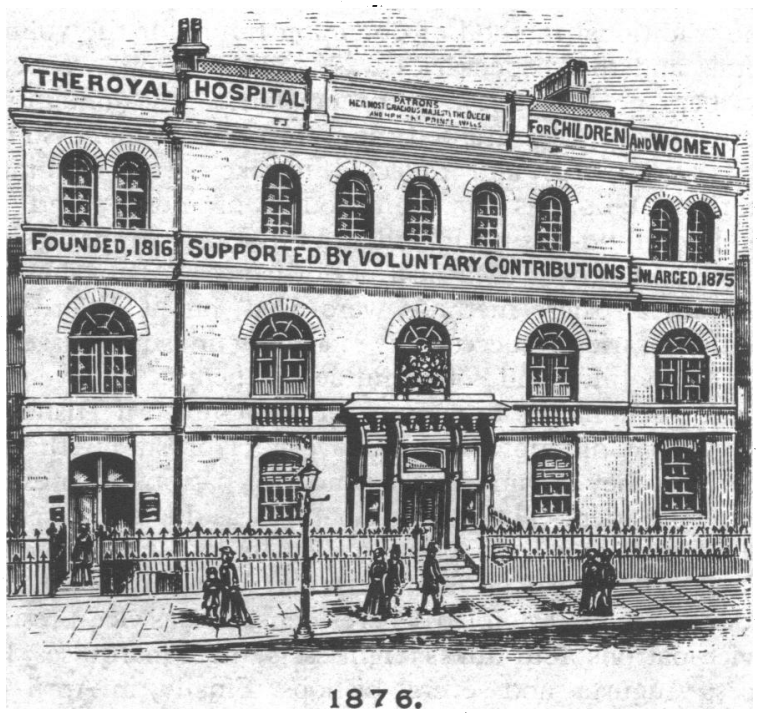

FIG 2-The Royal Hospital for Children and Women, Waterloo Bridge Road, as it appeared in $\mathbf{1 8 7 6 .}$

wholly uncritical belief, shared by most physicians at the time, in the effectiveness of early medical treatment of contagious fevers.

Davis had conceived the idea of a children's dispensary while he was detained in France after the Peace of Amiens. Characteristically, he wrote how fortunate it was that he had not heard of Armstrong's dispensary, for it would have "naturally damped his ardour in the prosecution of his purpose."s Being first, if possible, and, if not, being foremost, was important to Davis. He planned to establish a service for sick children throughout the metropolis and, he hinted, beyond London as well in time. The plan was to be based on a parent institution, and "branch 
stations" in strategic areas; later, when funds were sufficient, the parent institution would become a hospital. He could hardly have conceived a more ambitious plan, and, but for his premature death, it might have succeeded. The need for an instituion for sick children was undeniable; the mortality of children in London was appalling. In 1815, according to Davis, the population of children under 5 in London was 19560 and the deaths in this age group were $7116 . .^{6}$ The death rate for those aged under 5 was, Davis pointed out, "more than at any subsequent period of life." Most hospitals refused to admit children, and parents therefore would not take them to hospitals or dispensaries "expecting them to be neglected where grown-up persons were attended to." " Davis insisted that the area from which patients would be accepted would be unlimited-hence the "Universal" in the title-and that all urgent cases would be seen at once without letters of recommendation, "the only letter of introduction required being that which is written 'on the brow of misery'."

\section{Philanthropy and fund-raising}

At first Davis was the sole physician to the dispensary, but there were also two surgeons and a resident apothecary. The success of most dispensaries, however, depended less on clinical skill than on the ability to raise funds in the competitive world of philanthropy that existed in London in the first half of the nineteenth century. London had at least 19 dispensaries in 1818 and 25 hospitals ${ }^{8}{ }^{9}$; by 1831 there were 27 dispensaries, 37 hospitals, and about 30 related "paramedical" institutions, such as vaccine establishments, truss societies, refuges for the destitute and asylums for the blind, and homes for orphans and for the "recovery of health." 10 It was sometimes said that London had too many charities, particularly too many dispensaries, ${ }^{11}$ all of which depended on subscriptions from the minority of the population affluent enough to subscribe to charity.

The traditional method of obtaining funds for the voluntary hospitals and the dispensaries was to invite people to become subscribers or governors. In proportion to the amount they subscribed they were granted the right to recommend so many patients at one time, and if elected, to take part in running the institution. This was the main source of money, and other methods of fund-raising included anniversary dinners, charity sermons, and benefit theatrical performances. At the Universal Dispensary all these methods were used, but it differed from other dispensaries in successfully recruiting unusually large numbers of the nobility and "other influential people" to give money and lend their names in support of the Universal Dispensary. These people did not become governors or sit on the committees, but they became patrons and vice-patrons, or presidents and vice-presidents. The credit for this was due almost entirely to Davis who was a tireless letter writer. By 1821 he had recruited the Royal Dukes of Kent and Sussex as joint patrons, the Lord Mayor of London (ex officio) as president, and, as vice-presidents and vice-patrons, four dukes, eight earls, three marquises, $\mathrm{HRH}$ Princess Augusta, and several bishops. Finally, in April 1821, the King "bestowed his Royal Approbation and Patronage on this important and National Institution."12 Davis also wrote to the leaders of the royal colleges, for whom he created the title of "honorary directors". Here he was equally successful, recruiting among many others Sir Henry Halford, Dr John Latham PRCP, Matthew Baillie, William Heberden, Henry Cline, John Abernethy, and Astley Cooper. ${ }^{13}$ Even if Davis's love of the "great" was obsequious, it was effective; few accepted the invitation of patronage without sending money, and many seemed to take a genuine interest in the progress of the institution, judging by their letters.

\section{The years 1816-24}

The dispensary was open to children under the age of 12 . In the first year just under 2000 children were admitted to the charity, and total attendances were between seven and eight thousand. ${ }^{14}$ In July 1817 a second physician was needed; one of the applicants was Thomas Addison (later of Guy's Hospital) but, as the rules of the Dispensary stipulated that the physicians must either be licentiates or fellows of the Royal College of Physicians, he was not admitted as a candidate. Addison applied again at the next vacancy in May 1819 and, although he did not receive his licentiate until December 1819 , he was elected. The

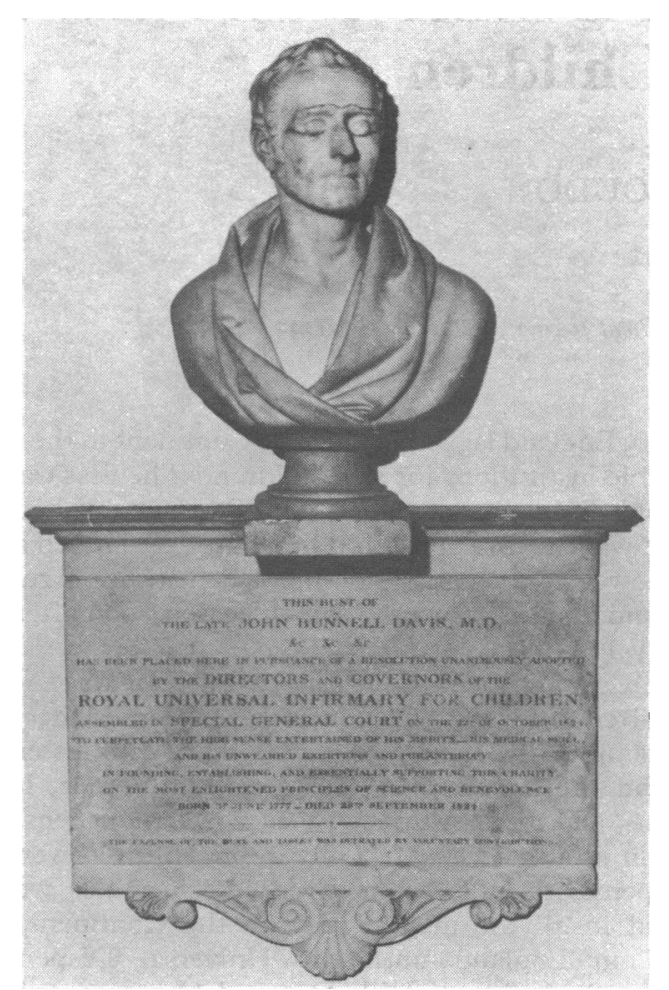

FIG 3-Commemorative bust of John Bunnell Davis (1777-1824), founder of the Universal Dispensary for Children.

committee, recognising his worth, took the unusual step of waiving the rule "because he was in progress [sic] of becoming a licentiate."15 Addison was the first of several distinguished physicians elected to the Universal Dispensary, including Thomas Copland, Robert Bentley Todd, and Charles West, the founder of Great Ormond Street Hospital.

By 1821 new attendances had risen to 3400 a year and total attendances averaged 250 each week; the records show that the children came from all over London. ${ }^{16}$ Teaching took place at the Dispensary, which had 34 pupils in the first four years; the Universal Dispensary for Children was an active and successful institution. Davis was proud of his achievement, and he was clearly upset when, in 1820 , he learnt that there were plans to open a rival institution called the "Royal Infirmary for Diseases of Children" (in fact a dispensary) ${ }^{17}$ in Marylebone. He tried to persuade the rival to add "Western" to its title to underline its parochial nature compared with the Universal Dispensary. ${ }^{18}$

The threat of competition also led Davis to implement his original plan for "branch stations." The first was opened immediately at the house of his brother, Benjamin Goodwin Davis (apothecary to the Surrey Dispensary from 1815 to 1820) in Southwark; others followed in Marylebone, Lambeth, Pentonville, and later in the City. By 1822 it was clear that the dispensary would have to move. The original premises were too small and becoming dilapidated. A new site was found, south of the Thames, on the east side of Waterloo Bridge Road at the corner of Stamford Street. The new building was to be much larger, consisting of four storeys, and as well as serving as a dispensary it was designed with two wards for inpatients. 
The rules of the institution were revised to include a nurse, and a system of charging parents a small fee for lodging when their children were admitted. The name was to be changed to the "Royal Universal Infirmary for Children," and the foundation stone was laid in 1823 by the Duke of York to the accompaniment of the band of the Grenadier Guards. Then, on 28 September 1824, shortly before the building was completed, John Bunnell Davis died suddenly. A commemorative bust and tablet (fig 3) was ordered to stand in the principal room of the new Infirmary. ${ }^{19}$ It is there today, sadly in need of cleaning, in the Royal Waterloo Hospital. It portrays a man with a quiff of hair, who looked young for his age, lean, tense, and determined.

\section{The new infirmary}

In 1776 Dr Johnson said: "Though many men are nominally entrusted with the administration of hospitals and other public institutions, almost all the good is done by one man, by whom the rest are driven on; owing to confidence in him and indolence in them." ${ }^{20}$ Davis was 47 when he died and he was sorely missed; those left to run the institution seemed lost, timid, and apathetic. Moreover, the new infirmary, which was completed by the end of 1824 , was burdened with a heavy debt; four years after it was completed there was still $£ 2000$ owing to the contractors. Meeting the cost of inpatients was out of the question; the wards and certain other rooms were converted and let, rather ineptly as it happened, to raise money. The branch stations were closed for economy, and gradually, over about 10 years, the debts were paid off. Meanwhile, the number of patients rose steadily and the medical staff was increased to three physicians, three surgeons, and the resident house surgeonapothecary.

By 1824 the yearly total of new patients was just under 5000 and total attendances about 20000 . It was reported to the committee that sometimes the crowds pressing through the narrow corridor overflowed into the physicians' rooms, as many as eight or ten children being in the room at once; the physicians objected, but the surgeons appeared not to mind. ${ }^{21}$ The income of the Infirmary did not increase and it was noticeable that the recruiting of "noble and influential people" as vice-presidents had virtually stopped with Davis's death. The expenses, however, increased with the larger number of patients, the drug bill amounting to one-third of total expenditure. Medical officers were told that they were overprescribing and asked to use the utmost economy. Under these circumstances all plans for new developments were postponed, and not until April 1843, nearly 20 years after the new Infirmary had opened, was the possibility of inpatients even discussed.

\section{Charles West and the Royal Universal Infirmary}

Charles West, who was appointed physician at the age of 26 in November $1842,{ }^{22}$ probably raised the subject of inpatients. He had had no particular experience of children's diseases, and it was at the Royal Universal Infirmary that he acquired the experience and enthusiasm that led to the foundation of Great Ormond Street Hospital. He did his best to revitalise and develop the Royal Universal Infirmary, and for six years he pressed for the opening of the wards. In principle, the committee agreed with him and entered many resolutions in the minutes saying so; they stated that they "regarded their work only half done until they could admit inpatients" and started a special "Hospital Fund" for the purpose. In practice, nothing happened; the wards would be opened one day, but not yet. There is no evidence to support the assertion that the wards were not opened because of the jealousy of practitioners in the district ${ }^{23}$; instead, it appears simply that the committee was possessed by apathy and timidity - chiefly apathy. The management committee, which met monthly, had 30 members, but the average number attending in 1844 was five, and on four occasions less than three, three being a quorum. ${ }^{24}$ The only consistent attender was Charles West. It is not surprising that in November 1849 a frustrated Charles West resigned, and within two months (January 1850) he had arranged the first meeting in the house of Dr Bence Jones that was to lead to the foundation of The Hospital for Sick Children Great Ormond Street. ${ }^{25}$

The committee of the Royal Universal Infirmary apparently knew little or nothing of the plans of Charles West because, on 22 February 1850, when the secretary read out an account published in The Times of "a meeting of gentlemen desirous of promoting a hospital for sick children" they were greatly shocked, and at last were driven to action. The hospital fund was reopened and letters of appeal were sent to every member of both Houses of Parliament and to all judges, barristers, alderman, bankers, magistrates, and members of the nobility in London. Four thousand letters were delivered. The committee was not to know it, but it was too late; through indolence they had lost the best physician they had ever had. If they had listened to him and acted, the address that is synonymous with a famous paediatric institution might have been Waterloo Road instead of Great Ormond Street.

The appeal succeeded in raising $£ 1179$ in eight months but still the committee procrastinated, and when the first inpatient was admitted it was without the knowledge or consent of the committee. It was an act of bold defiance by a young surgeon, only recently elected in June 1851, called John Cooper Forster. ${ }^{26}$ On 12 August 1851 he attended a boy at the Infirmary with a bladder stone. On 19 August, after quietly preparing a room at the Infirmary, he admitted the boy and, with a colleague's help, operated and removed the stone. The boy ran a sharp and worrying fever, but he recovered and was discharged, cured, on 19 October. Then and only then did Forster write to inform the committee, and his letter is a model of a defiant apology. ${ }^{27}$ The committee responded (predictably, for they had done so before) by setting up a subcommittee to consider immediately opening a four-bedded ward. The subcommittee produced a good and detailed report in favour of the proposal; the full committee turned it down. Once more it was a case of sometime, but not yet. It was only in 1856, when the Royal Universal Infirmary had received from the Hayles Estate a yearly bequest of $£ 450$ that inpatients were admitted. The bequest stipulated that there should be at least 16 beds in the Infirmary and that women should be treated as well as children. ${ }^{28}$ The committee showed the remnants of some spirit when it refused the suggestion that the name should be changed to the "Royal Infirmary for Women and Children," so "Children and Women" it remained, but its rules, constitution, and character changed with the bequest. Although it had been called an Infirmary for most of the time, for 40 years it had been a children's dispensary, and over 200000 children had attended as outpatients since it was first established.

\section{Conclusion}

The Universal Dispensary for Children, much more than Armstrong's Dispensary for the Infant Poor, established the principle of charitable care for the sick children of the poor. Thereby it played a major part in the foundation of children's hospitals in England; in 1850 there were none; by 1870 there were at least six in London and six in the provinces. Nevertheless, the Universal Dispensary failed to live up to the high hopes of its founder and lost the opportunity of becoming England's first hospital for sick children.

Institutions that fail, even partially, are apt to be neglected, yet their failure may reveal more about the difficulties of medical care in the past than the histories of successful and famous institutions. The history of the Universal Dispensary shows the penalty of losing, through premature death, the man on whom the institution depends. It shows the difficulties of financing a dispensary, and the even greater difficulties of converting a dispensary to a hospital. Highmore, in 1810, maintained that dis- 
pensaries could treat 50000 patients for $£ 5000$, which was less than a third of the cost of a single hospital "which relieves scarcely 6000 a year." ${ }^{29}$ Nevertheless, all over London, dispensaries during 1820-30 were experiencing great difficulty in making ends meet. Most of all, however, the Universal Dispensary demonstrated an aspect of medical institutions that is often neglected-the importance, for good or evil, of the management committee. Unless the committee contained sufficient energetic, able, and dedicated men, even physicians of the calibre of Robert Bentley Todd and Charles West could do little to develop the institution in the way planned by its founder, John Bunnell Davis, to whom too little credit has been given as a pioneer in the care of sick children in England. In the United Nations' Year of the Child, 1979, it is appropriate that Davis and his Dispensary should be remembered.

This paper is part of a historical study of dispensaries in England between 1770 and 1850 which is being undertaken with the aid of a grant from the Wellcome Trust. I should like to thank the Wellcome Trust, and also express my deep gratitude to Dr Charles Webster, of the Wellcome Unit for the History of Medicine in the University of Oxford, for invaluable help and encouragement with this research. I also thank St Thomas's Hospital for permission to publish extracts from the records of the Royal Waterloo Hospital, and the Vicar of Clare (the Rev M G Woodward) for providing information from the baptismal register.

Illustrations are reproduced with kind permission of St Thomas's Hospital archives.

\section{Bibliography}

1 Coughtrey, A H, Hospital Gazette, 1916, 13 (No 2), 21.

2 Armstrong, G, 1777. An Account of the Diseases Most Incident to Children, to which is added an essay on nursing, with particular view to infants brought up by hand; also a short account of the Dispensary for the Infant Poor. London, 1808 edn.

${ }^{3}$ Maloney, W J, George and fohn Armstrong of Castleton. London, Livingstone, 1954.
${ }^{4}$ Davis, John Bunnell, (1777-1824). MD Montpellier, 1803. MD Edin, 1808. LRCP, 1810. Dictionary of National Biography, vol 14, p 168. Munk, W, The Roll of the Royal College of Physicians of London, vol 3, p 95. London, RCP, 1878

${ }^{5}$ Davis, J B, Annals Historical and Medical of the First Four Years of the Universal Dispensary for Children, p 18. London, 1821.

${ }^{6}$ Davis, J B, ibid, p 12.

7 Davis J B, ibid, p 10.

${ }^{8}$ Granville, A B, A Report on the Practice of Midwifery at the Westminster General Dispensary during 1818, appendix. London, 1819.

9 Fohnstone's London Directory, 1818.

10 Robson's London Directory, 1831.

11 Gentleman's Magazine, part 1, p 409. London, 1816.

12 The Universal Dispensary for Sick Children: minutes of the monthly and quarterly committees, 1816-21.

${ }^{13}$ Minutes of committee, July 1821.

14 Davis, J B, ibid, p 144

${ }^{15}$ Minutes of monthly and special committees, 1819.

${ }^{16}$ Davis, J B, ibid, p 196. Footnote giving the parishes of origin of patients attending the dispensary.

17 Establisned, probably, by Augustus Bozzi Granville, physician accoucheur to the Westminster General Dispensary. Dictionary of National Biography, vol 22, p 143.

18 Minutes of monthly committees, May-June 1820.

19 The Dictionary of National Biography and Munk's Roll record his date of birth as 1780 ; the tablet records it as 1777 , and this date is confirmed as correct by the baptismal register at Clare in Suffolk, where he was baptised on 17 July 1777.

${ }^{20}$ Boswell, J, Life of fohnson, vol 2, p 36. London, OUP, 1904.

${ }^{21}$ Minutes of monthly committee, Dec 1842.

${ }^{22}$ Minutes of special committee, Nov 1842. Charles West had previously applied in 1840 but was ineligible, not holding the Licence of the Royal College of Physicians of London at the time.

${ }^{23}$ British Medical fournal, 1898, 1, 921. Charles West: obituary notice.

${ }^{24}$ Minutes of monthly committee, 1844. In this respect, 1844 was typical of the period 1840-52.

${ }^{25}$ Higgins, T Twistington, Great Ormond Street 1852-1952. London, Odhams, 1952.

${ }^{26}$ John Cooper Forster, FRCS. Assistant surgeon to Guy's Hospital, 1855; full surgeon, $1870-80$.

27 Minutes of monthly committee, Oct 1841

${ }^{28}$ Minutes of monthly and special committees, 1853-6.

${ }^{29}$ Highmore, A, Pietas Londinensis. The History, Design and Present State of the Various Public Charities in or near London. London, 1810.

(Accepted 12 February 1979)
Do any vaccines given to the mother affect a baby who is being breast-fed? Is there any evidence that killed vaccines administered during pregnancy (cholera or tetanus) have any serious effects on the pregnancy?

Breast milk is a rich source of maternal antibodies, contributing to the infant's immunity. Vaccines given to the mother in pregnancy will of course benefit the infant by the transplacental route whether or not he is breast-fed, but will probably be more beneficial to the breast-fed infant. Killed vaccines, such as those against cholera and tetanus, can safely be given during pregnancy.

Has any recent research shown ethylene or ethylene oxide to be carcinogenic? If so, in what concentrations?

The International Agency for Research on Cancer reviewed the data available up to 1976 for assessing the carcinogenicity of ethylene oxide. ${ }^{1}$ No information from epidemiological or clinical studies was then available, and though tests in mice (by application to the skin) and rats (by subcutaneous injection) had given negative results these were not regarded as providing sufficient evidence for assurance of non-carcinogenicity. In January 1978 the USA's Food and Drug Administration announced its intention to establish maximum residue limits for ethylene oxide and its two major reaction products, ethylene chlorohydrin and ethylene glycol, and maximum daily exposure levels of these compounds for drug products. ${ }^{2}$ The Environmental Protection Agency simultaneously issued a "Notice of Rebuttable Presumption" against the new or continued registration of pesticides containing ethylene oxide. A position paper was published with these announcements reviewing relevant toxicological data. According to this review ethylene oxide has been shown to be mutagenic in various bacterial test systems, in plants, and in Drosophila and it also causes chromosomal aberrations in rats. Also, rats exposed to ethylene oxide by inhalation at levels of $200 \mathrm{ppm}$ or more show atrophic changes in the testis. No genital disorders and no evidence of increased cancer risks have been seen in a group of 37 operators exposed to 5-10 ppm ethylene oxide for an average of 10.7 years. Since the announcements in the Federal Register in January 1978, however, three cases of leukaemia among 100 workers at an ethylene oxide plant in Hallsberg have been reported from Sweden. ${ }^{3}$ According to the Federal Register further carcinogenicity tests in animals are in progress on ethylene oxide and its reaction products, and Chemical $W e e k$ has reported that an industry-wide study on the effects of exposure in man is under way at the Carnegie-Mellon Institute in the USA. Work in Sweden has shown that ethylene may be converted to ethylene oxide in vivo."

${ }^{1}$ International Agency for Research on Cancer, Evaluation of Carcinogenic Risk of Chemicals to Man, monograph No 11. Lyon, IARC, 1976.

${ }^{2}$ Federal Register Document 78

- Ehrenberg, L, et al, Mutation Research, 1977, 45, 175.

Is there any convincing evidence linking sarcoidosis with local deposits of heavy metals?

There is nothing to suggest that heavy metals are concerned in the pathogenesis of the systemic disease sarcoidosis. In patients with this disease local granulomatous reactions may occur around mineral particles in the tissues, notably the skin. The most familiar example of this is provided by the infiltrations of old scars containing siliceous particles that may develop during the course of active sarcoidosis. A few cases of similar infiltrations in old tattoos have been recorded. These seem to be reactions to pigments, some of which may be compounds of heavy metals. This is the only evidence I know linking heavy metals in any way with sarcoidosis. 